\title{
Uso de biomateriais e rosuvastatina tópica aumenta angiogênese de feridas cirúrgicas
}

\section{em coelhos}

\author{
Use of biomaterials and topical rosuvastatin increases angiogenesis of surgical wounds in rabbits \\ El uso de biomateriales y rosuvastatina tópica aumenta la angiogénesis de heridas quirúrgicas en \\ conejos
}

Recebido: 19/12/2020 | Revisado: 24/12/2020 | Aceito: 14/01/2021 | Publicado: 17/01/2021

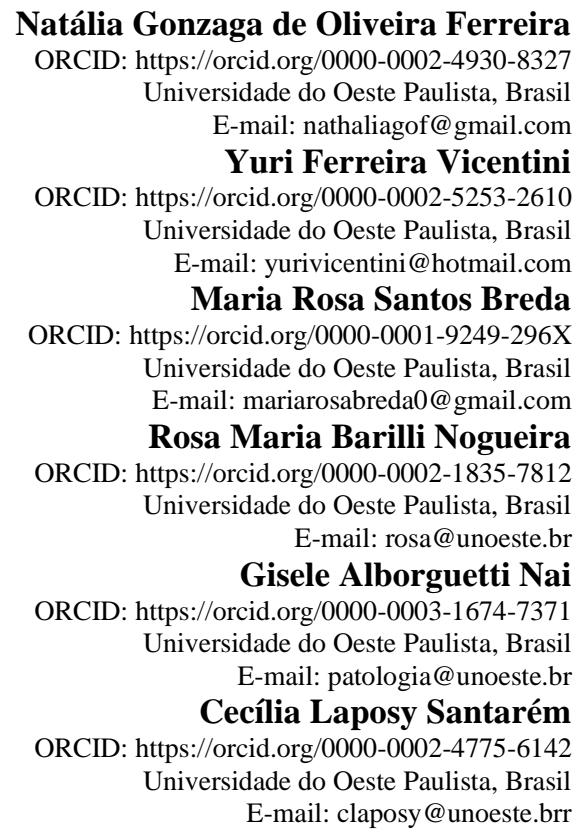

\begin{abstract}
Resumo
Estudos têm sido realizados para verificar os efeitos de biomateriais, como o plasma rico em plaquetas (PRP) e a fibrina rica em plaquetas (FRP) e a sua contribuição para o processo de cicatrização de feridas por meio da liberação de fatores de crescimento que têm propriedades de indução de regeneração tecidual. Muitas evidências também se mostram favoráveis ao uso tópico da rosuvastatina (RSV) em lesões de pele, por modificar de forma positiva o fluxo sanguíneo basal tecidual. No entanto, não está claro se este efeito está envolvido no aumento do fluxo sanguíneo e por consequência uma melhora no processo cicatricial. Neste sentido, o presente estudo analisou a quantidade de fibroblastos e número de vasos em feridas induzidas experimentalmente em coelhos após tratamento com e sem associação dos biomateriais e RSV. A hipótese baseia-se que o uso tópico de um fármaco hipolipemiante associado a um biomaterial possa aumentar a quantidade de fibroblastos e angiogênese após lesão experimentalmente induzida, e com isso aumentando a colagenização para produção de uma cicatriz mais homogênea. Verificou-se que a associação da FRP e RSV promoveu um efeito aditivo aumentando em $135 \%$ a angiogênese. O uso da RSV isolada também proporcionou um aumento de 77\% na quantidade de fibroblastos. Concluiu-se que tanto a FRP quanto a RSV possuem bons efeitos cicatrizantes, de tal forma que a associação entre elas foi benéfica e demonstrou um possível efeito aditivo.
\end{abstract}

Palavras-chave: Plasma rico em plaquetas; Fibrina rica em plaquetas; Estatinas; Cicatrização; Neovascularização.

\begin{abstract}
Studies have been conducted to verify the effects of biomaterials such as platelet-rich plasma (PRP) and platelet-rich fibrin (PRF) and their contribution to the wound healing process by releasing growth factors that have properties of tissue regeneration. Many evidences are also favorable to the topical use of rosuvastatin (RSV) in skin lesions, by positively modifying the basal tissue blood flow. However, it is unclear whether this effect is involved in increased blood flow and consequently an improvement in the healing process. In this sense, the present study analyzed the amount of fibroblasts and number of vessels in wounds experimentally induced in rabbits after treatment with and without
\end{abstract}


association of biomaterials and RSV. The hypothesis is that the topical use of a lipid-lowering drug associated with a biomaterial may increase the amount of fibroblasts and angiogenesis after experimentally induced injury, thereby increasing collagenization to produce a more homogeneous scar. It was found that the association of PRF and RSV promoted an additive effect, increasing angiogenesis by $135 \%$. The use of RSV alone also provided a $77 \%$ increase in the amount of fibroblasts. It was concluded that both PRF and RSV have good healing effects, such that the association between them was beneficial and demonstrated a possible additive effect.

Keywords: Platelet-rich plasma; Platelet-rich fibrin; Statins; Healing; Neovascularization.

\section{Resumen}

Se han realizado estudios para verificar los efectos de biomateriales como el plasma rico en plaquetas (PRP) y la fibrina rica en plaquetas (FRP) y su contribución al proceso de cicatrización de heridas al liberar factores de crecimiento que tienen propiedades de regeneración tisular. Muchas evidencias también son favorables al uso tópico de rosuvastatina (RSV) en lesiones cutáneas, al modificar positivamente el flujo sanguíneo del tejido basal. Sin embargo, no está claro si este efecto está involucrado en un aumento del flujo sanguíneo y, en consecuencia, en una mejora en el proceso de curación. En este sentido, el presente estudio analizó la cantidad de fibroblastos y el número de vasos en heridas inducidas experimentalmente en conejos tras el tratamiento con y sin asociación de biomateriales y RSV. La hipótesis es que el uso tópico de un fármaco hipolipemiante asociado con un biomaterial puede aumentar la cantidad de fibroblastos y la angiogénesis después de una lesión inducida experimentalmente, aumentando así la colagenización para producir una cicatriz más homogénea. Se encontró que la asociación de FRP y RSV promovió un efecto aditivo al aumentar significativamente la angiogénesis. Se encontró que la asociación de FRP y RSV promovió un efecto aditivo, aumentando la angiogénesis en un $135 \%$. El uso de RSV solo también proporcionó un aumento del $77 \%$ en la cantidad de fibroblastos. Se concluyó que tanto el FRP como el RSV tienen buenos efectos curativos, por lo que la asociación entre ellos fue beneficiosa y demostró un posible efecto aditivo.

Palabras clave: Plasma rico en plaquetas; Fibrina rica en plaquetas; Estatinas; Cicatrización; Neovascularización.

\section{Introdução}

Os concentrados plaquetários como plasma rico em plaquetas (PRP) e fibrina rica em plaquetas (FRP), constituem os principais hemoderivados empregados na medicina regenerativa. O PRP, criado por Marx et al. (1998), é amplamente estudado e com ênfase na cicatrização de feridas demonstra-se uma excelente ferramenta a ser empregada (Barionuevo et al., 2015; Abegão et al., 2015, Santos et al., 2016. Taniguchi et al., 2018).

A FRP, considerada a segunda geração de concentrados plaquetários, possui resultados promissores em vários aspectos analisados, de tal forma que fomentam pesquisas nas mais diversas áreas, já sendo relatada sua utilização na dermatologia (Chiaravalloti et al., 2018) medicina esportiva (Ehrenfest et al., 2014) implantologia (Dohle et al., 2018) e em procedimentos estéticos (Cieslik-Bielecka et al., 2012).

Para que ocorra a cicatrização de maneira saudável, são essenciais a migração e proliferação celulares para a formação da matriz extracelular, constituída principalmente por colágeno. Estudos comprovam que as estatinas além das características hipolipemiantes, possuem atividades de proliferação celular (Lin et al., 2012) e proteção endotelial (Moraes et al., 2013) além de outros efeitos pleiotrópicos como anti-inflamatório (Pradeep et al., 2015) antioxidante (Santos et al., 2014), imunomodulador (Zhang et al., 2012) e cicatrizante, promovendo, por mecanismos não totalmente elucidados, o auxílio à cicatrização tecidual (Raposio et al., 2015).

A rosuvastatina (RSV) por ser uma nova estatina hidrofílica sintética de segunda geração, com alta eficiência na redução do colesterol sérico e com potente efeito anti-inflamatório, sendo mediador vascular do óxido nítrico endotelial e redutor dos níveis de proteína C reativa (Pradeep et al., 2015) foi utilizada neste estudo a fim de ser associada ou não aos biomateriais PRP e FRP para verificar sua ação no processo cicatricial. A hipótese seria avaliar a quantidade de fibroblastos e capilares neoformados em feridas induzidas experimentalmente em coelhos após o tratamento com e sem a associação de FRP ou PRP com RSV. 


\section{Metodologia}

Para este estudo foram selecionados 16 coelhos adultos, machos, clinicamente saudáveis, da raça Nova Zelândia, peso médio $3,0 \pm 1,0 \mathrm{~kg}$, mantidos em gaiolas individuais, com temperatura ambiente de $22^{\circ} \mathrm{C} \pm 2^{\circ} \mathrm{C}$ e fotoperíodo ( 12 horas claro/escuro) controlados, com água e ração ad libitum. Os 16 coelhos selecionados foram divididos em dois grupos com n=8/(grupo PRP) e n=8/(grupo FRP). O trabalho foi aprovado pela comissão de Ética e Uso de Animais (protocolo número 4332) da Universidade do Oeste Paulista-Presidente Prudente, São Paulo, Brasil.

Para o procedimento anestésico, os coelhos foram contidos manualmente para realização da tricotomia da região dorsal direita e esquerda. Em seguida, os animais foram anestesiados (intramuscular-IM) com uma associação de cloridrato de Xilazina a $2 \%$ (Xilazin ${ }^{\circledR} 2 \%$ ) e Cloridrato de Zolazepam $\left(\right.$ Zoletil $^{\circledR} 50$ ) nas doses de $5 \mathrm{mg} / \mathrm{Kg}$ e $15 \mathrm{mg} / \mathrm{Kg}$ intramuscular, respectivamente. Feito isso, aplicou-se previamente $0,1 \mathrm{~mL}$ de anestésico local (cloridrato de lidocaína a $2 \%$ com vasoconstritor) no local de cada lesão.

Com os animais anestesiados, a pele foi demarcada em quatro locais com auxílio de caneta utilizado um punch de 8mm para realização das feridas cirúrgicas. Os fragmentos foram retirados com auxílio de uma pinça anatômica, preservando a musculatura (Barrionuevo et al., 2015). A ferida considerada controle (lado esquerdo superior) foi tratada com solução de cloreto de sódio a $0,9 \%$. A lesão do lado esquerdo inferior recebeu o gel de RSV a 1,2\%. A ferida do lado direito superior foi tratada com PRP autólogo na forma gel ou FRP e a ferida do lado direito inferior recebeu gel de RSV e PRP autólogo gel ou FRP (Figura 1). Em seguida foi colocado um curativo sobre as quatro feridas (lado direito e esquerdo/ superior e inferior) com atadura de Rayon estéril e curativo adesivo (Band $\mathrm{Aid}^{\circledR}$ ).

Figura 1. Demonstração das feridas confeccionadas por punch no dorso dos animais e respectivos tratamentos: Controle (solução fisiológica), biomaterial (PRP ou FRP); RSV (rosuvastatina); biomaterial+RSV (PRP ou FRP).

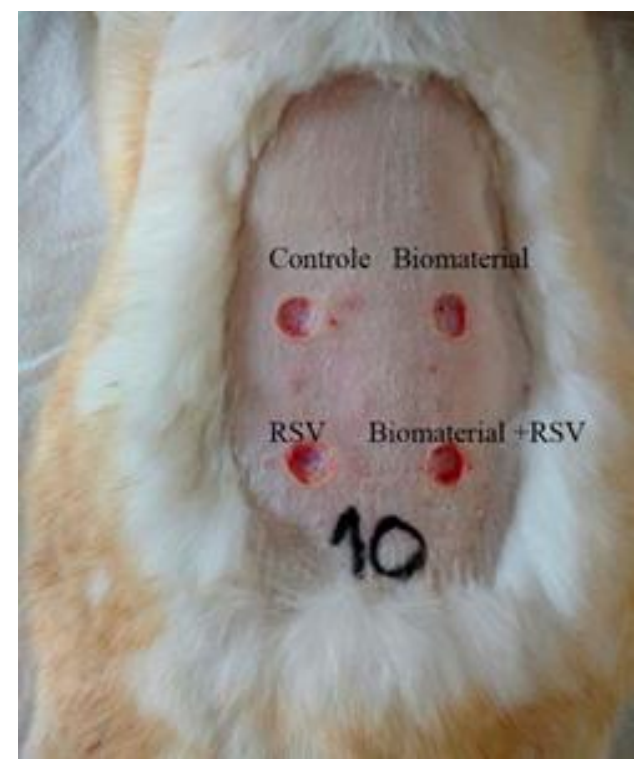

Fonte: Autores.

Após o procedimento cirúrgico, os animais receberam analgésico cloridrato de Tramadol, na dose de 0,5mg/Kg, IM, 2 vezes ao dia durante 3 dias consecutivos, a fim de minimizar o desconforto inicial. A primeira troca dos curativos foi feita 3 dias após a indução das feridas e este segundo curativo permaneceu por mais quatro dias. A partir disso, os tratamentos ocorreram a cada 4 dias, até completarem 16 dias de experimento. A partir disso, as trocas ocorreram a cada 4 dias, segundo 
protocolo estabelecido por Vendramin et al. (2010) até completarem 16 dias de experimento. No $17^{\circ}$ dia, prosseguiu-se com a realização de biópsia da ferida para avaliação, utilizando punch de $8 \mathrm{~mm}$.

Para a formulação do gel de rosuvastatina na concentração de 1,2\% utilizou-se um solvente compatível para a diluição da droga, e posteriormente preparado um gel de polímero de metilcelulose, (gel aristoflex®, São Paulo, Brasil), com 20\% de glicerina, que serviu como veículo para a rosuvastatina.

A confecção do gel foi realizada segundo Grover et al. (2016), aquecendo a solução em banho-maria a $50-60^{\circ} \mathrm{C}$ e homogeneizando o polímero com o solvente e a droga para que não houvesse a cristalização do ativo. Formulou-se também a RSV a 1,2\% na forma liquida a fim de ser incorporado ao PRP e posteriormente todo o material foi transformado em gel com a adição do gluconato de cálcio.

Após procedimento anestésico, colheu-se $8 \mathrm{~mL}$ de sangue proveniente da veia auricular utilizando scalp 25G. O material foi transferido para dois frascos contendo o anticoagulante citrato de sódio. Deste material foi retirada uma alíquota para a contagem automática de plaquetas (contador automático Sysmex Poch Diff 100iV- Roche) e depois centrifugado, inicialmente a 200G (centrífuga Excelsa Baby 206R) durante 10 minutos para formação de dois níveis: toda a fração correspondente ao plasma mais $200 \mu \mathrm{L}$ da fração vermelha foi transferida para outro tubo para nova centrifugação (400G por 10 minutos).

Nesta segunda etapa formaram-se dois níveis distintos: um superior com coloração levemente amarelado denominado plasma pobre em plaquetas (PPP) e um inferior, avermelhado. Retirou-se o PPP e do restante foi realizada nova contagem de plaquetas, com o objetivo de verificar se houve concentração superior a seis vezes do inicial (Vendramin et al., 2009). Após constatação da concentração plaquetária adequada, foram preparados dois tubos: um contendo $200 \mu \mathrm{L}$ de PRP líquido, 200 $\mu \mathrm{L}$ de rosuvastatina líquida e $100 \mu \mathrm{L}$ de gluconato de cálcio a 10\%. O segundo tubo contendo $400 \mu \mathrm{L}$ de PRP líquido e $100 \mu \mathrm{L}$ de gluconato de cálcio a 10\%, sendo que para ambos os frascos o volume final de PRP em gel foi de 0,5mL (Figura 2). 
Figura 2. A- Tubos contendo anticoagulante citrato de sódio, com sangue proveniente da veia auricular do coelho. B- Aspecto do sangue após a primeira centrifugação (200G). C- Tubo após segunda centrifugação (400G). D- Tubos contendo PRP e PRP+RSV, já transformados na forma gel, prontos para aplicação nas feridas.

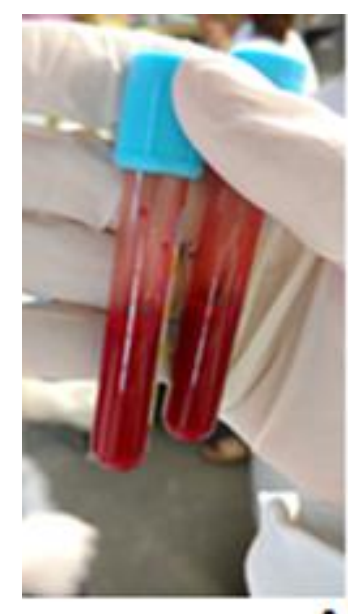

A

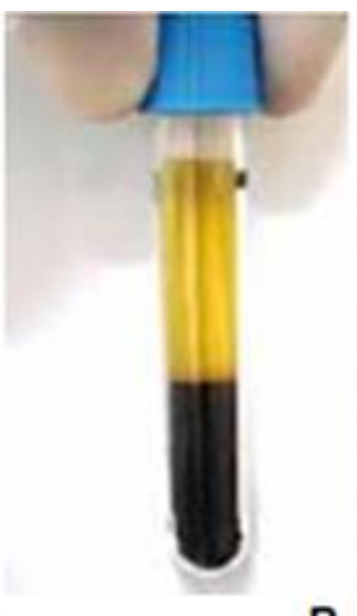

B

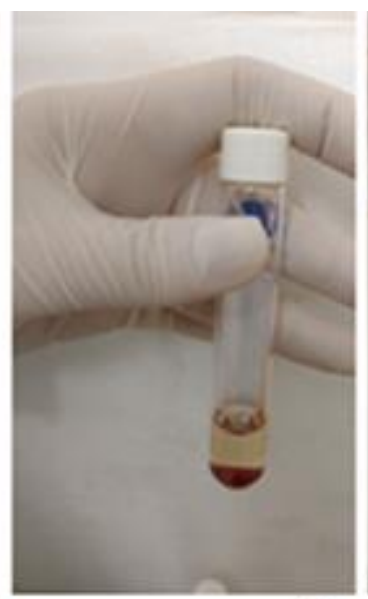

C

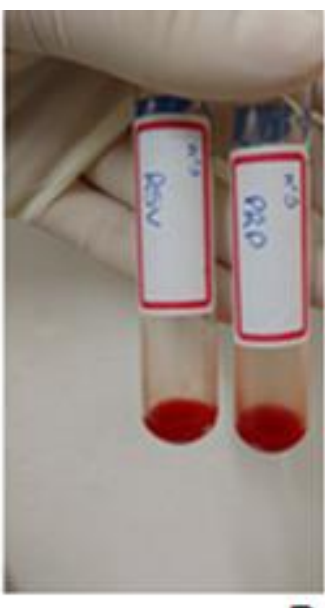

D

Fonte: Autores.

Para o preparo da fibrina rica em plaquetas (FRP) foram coletados $8 \mathrm{~mL}$ de sangue periférico da veia auricular, utilizando scalp 25G coletados e acondicionados em dois tubos sem adição de anticoagulante. Após a coagulação natural, como descrito por Azevedo (2014) realizou-se a centrifugação em uma única vez a 200G (Excelsa Baby 206R, São Paulo, São Paulo), por 10 minutos. Formado o gel de fibrina, este foi separado dos demais componentes e utilizado como tratamento das feridas superior e inferior direito (Figura 3).

Figura 3. A: Centrifugação da amostra a $200 \mathrm{G}$ por 10 minutos. B: Formação do gel de fibrina (seta).
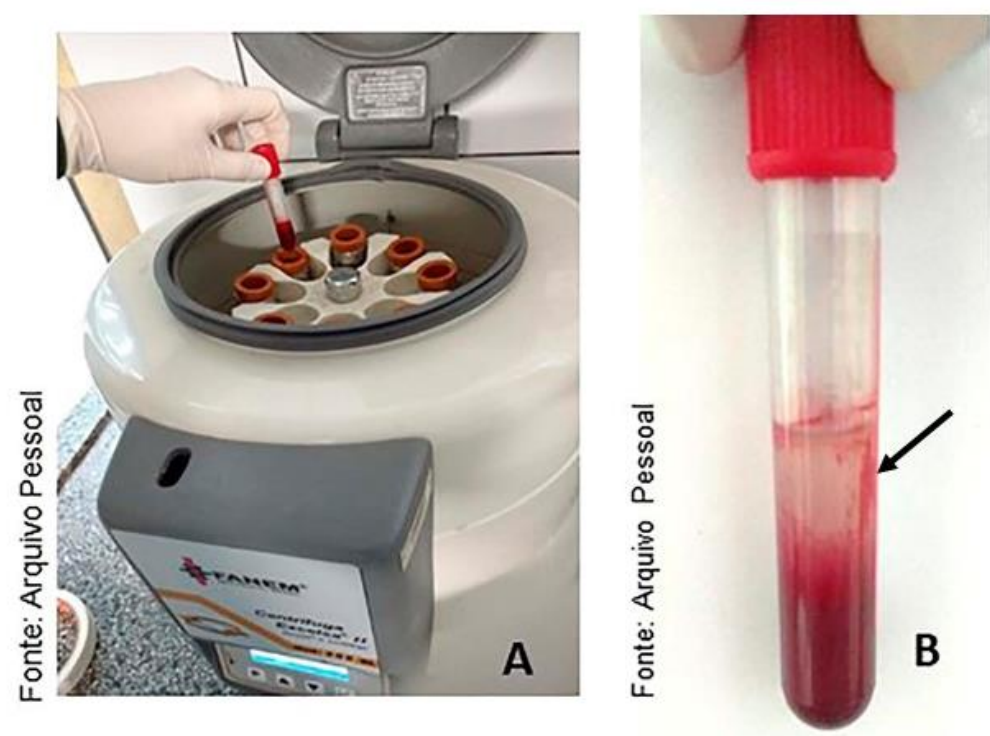

Fonte: Autores.

Para a avaliação histológica, as amostras de pele foram fixadas em solução de formol tamponado a $10 \%$ por 24 horas. 
Research, Society and Development, v. 10, n. 1, e32510111327, 2021

(CC BY 4.0) | ISSN 2525-3409 | DOI: http://dx.doi.org/10.33448/rsd-v10i1.11327

Após fixação, o tecido foi incluído em blocos de parafina, obtendo-se a seguir 4 cortes histológicos de $4 \mu \mathrm{m}$ de cada animal que foram corados com solução de Hematoxilina-Eosina (H/E) para aferição do colágeno. Nos fragmentos coletados após a eutanásia dos animais (M17), com o software Motic ${ }^{\circledR}$ (British Columbia, Canada) capturaram-se imagens na quais se realizou na derme a contagem de fibroblastos no aumento de 400X, por meio da média somatória entre onze campos observados de cada amostra (Vendramin et al., 2010). Da mesma forma realizou-se a contagem de vasos sanguíneos, mas na objetiva de 100X. Todas as avaliações foram feitas por um único observador e de forma cega.

Previamente às análises estatísticas, todos os grupos foram submetidos ao teste de Shapiro-Wilk para validação do pressuposto de normalidade dos dados, pelo qual se verificou que as variáveis apresentaram distribuição não-paramétrica. As feridas do controle e as dos diferentes tratamentos foram comparados pelo teste de Kruskall-Wallis e dentro de cada grupo, com contrastes pelo método de Student-Newman-Keuls. Adotou-se o nível de significância de p<0,05.

\section{Resultados}

No que se refere aos fibroblastos (Figura 4), verificou-se um incremento na quantidade destas células de $77 \%$ e $55 \%$, respectivamente, nas feridas que receberam a RSV $(238,4 \pm 37,7)$ e nas tratadas com a associação RSV+ FRP $(209,3 \pm 43,4)$, em relação às feridas tratadas com FRP $(134,3 \pm 19,7)$ ou solução fisiológica $\left(135,4^{\mathrm{a}} \pm 26,4\right)$. 
Figura 4. A: Média E Desvio-Padrão Da Quantidade De Fibroblastos De Feridas De Coelhos Tratadas Ou Não Com Biomateriais E Rsv. B:Fotomicroscopia Mostrando A Quantidade De Fibroblastos (Hematoxilina/Eosina, Aumento De 400x). Controle, Frp: Fibrina Rica Em Plaquetas, Rsv: Rosuvastatina, Frp+Rsv: Fibrina Rica Em Plaquetas E Rosuvastatina. * P<0,05 Em Relação Ao Controle.

A

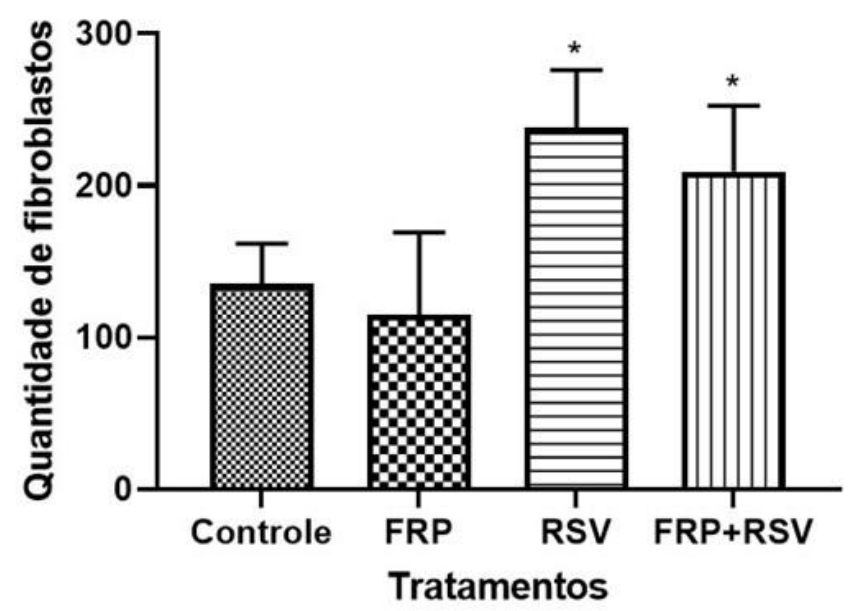

B
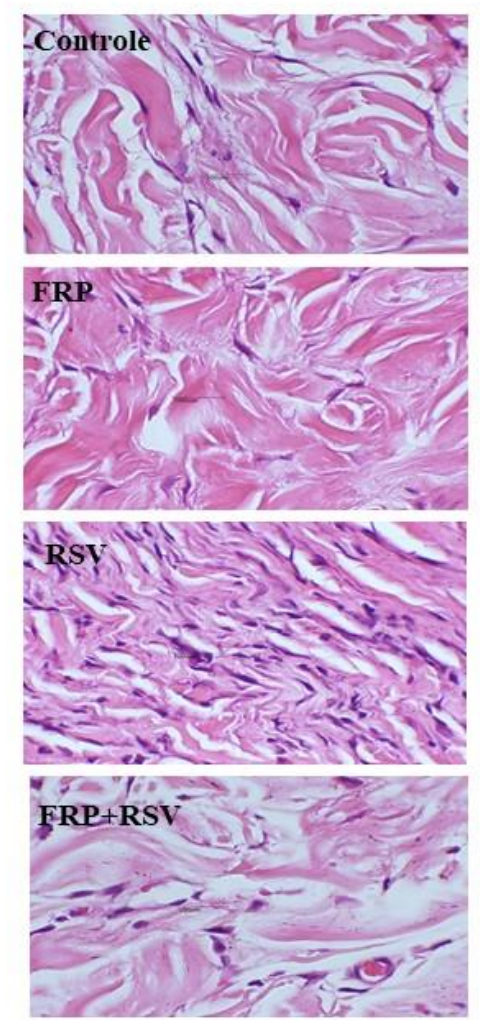

Fonte: Autores.

Na avaliação da angiogênese (Figura 5), verificou-se aumento significativo no número de vasos neoformados nas feridas tratadas com FRP $(17,67 \pm, 1,75)$, RSV $(12,66 \pm 2,16)$ e associação FRP+RSV $(20,00 \pm 4,61)$, equivalente a aproximadamente $110 \%$, $45 \%$ e $135 \%$, respectivamente, das médias obtidas nas feridas controle $(8,50 \pm 2,58)$. 
Figura 5. C: Média E Desvio-Padrão Da Quantidade De Vasos De Feridas De Coelhos Tratadas Ou Não Com Biomateriais E Rsv. D: Fotomicroscopia Mostrando A Quantidade De Vasos (Hematoxilina/Eosina, Aumento De 100x). Controle, Frp: Fibrina Rica Em Plaquetas, Rsv: Rosuvastatina, Frp+Rsv: Fibrina Rica Em Plaquetas E Rosuvastatina.
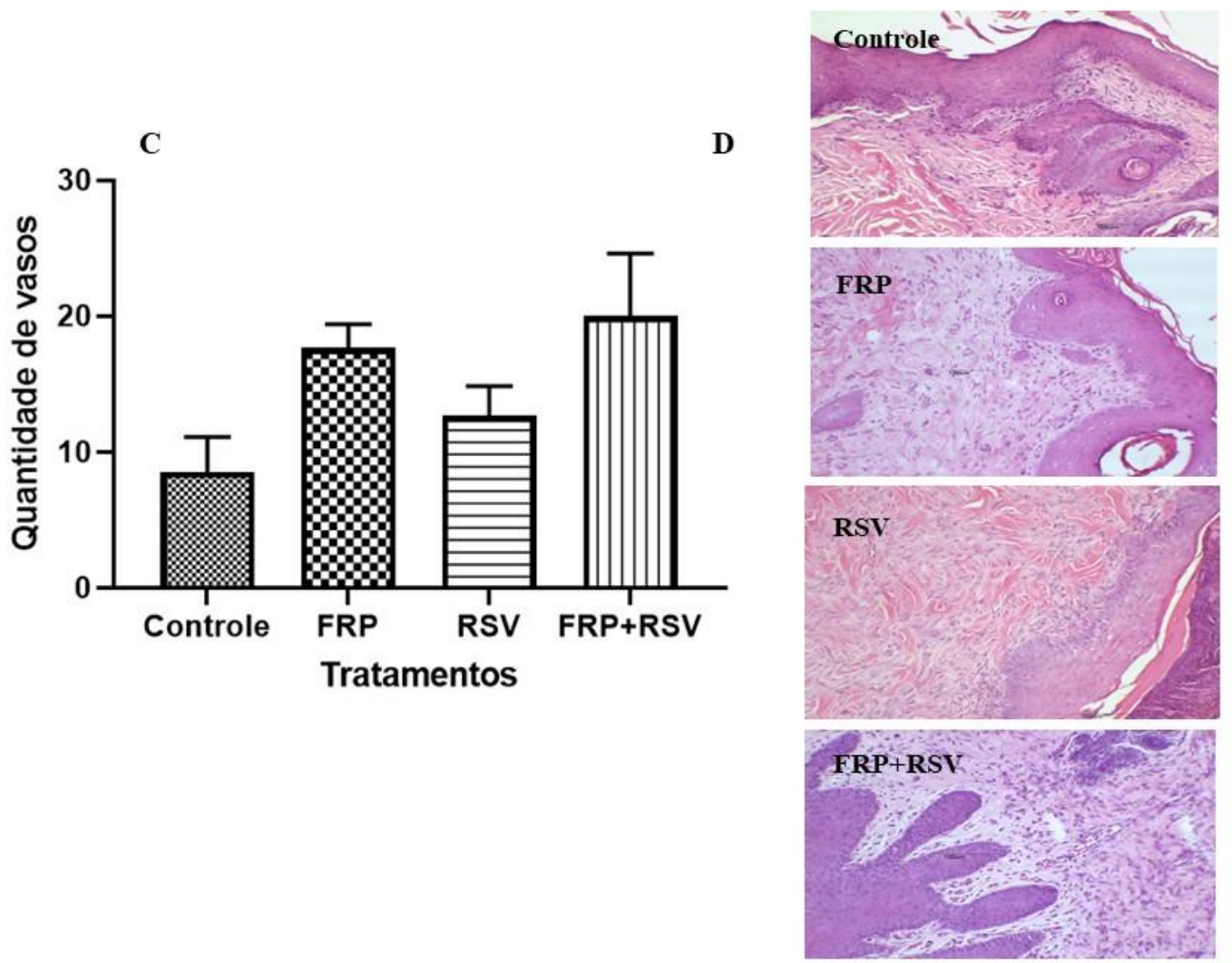

Fonte: Autores.

Em relação ao tratamento com PRP, verificou-se que tanto o biomaterial como a RSV, utilizados sozinhos ou em associação, não provocaram alterações significativas na quantidade de fibroblastos. Os valores médios encontrados foram, respectivamente, de: $185,8 \pm 23,3,211,0 \pm 61,0$ e 187,3 $\pm 51,4$, quando comparados à ferida controle (155,0 020,5$)$. Resultados semelhantes foram obtidos na avaliação da angiogênese (Figuras 6 e 7), sem diferenças significativas nas médias de PRP $(19,5 \pm 3,7), \operatorname{RSV}(16,1 \pm 8,1)$ e associação $(18,6 \pm 12,1)$ em relação às feridas controle $(16,6 \pm 5,6)$. 
Figura 6. E: Média e desvio-padrão da quantidade de fibroblastos de feridas de coelhos tratadas ou não com biomateriais e RSV. F:Fotomicroscopia mostrando a quantidade de fibroblastos (Hematoxilina/Eosina, aumento de 400x). Controle, PRP: plasma rico em plaquetas, RSV: rosuvastatina, $\mathrm{PRP}+\mathrm{RSV}$ : plasma rico em plaquetas e rosuvastatina.
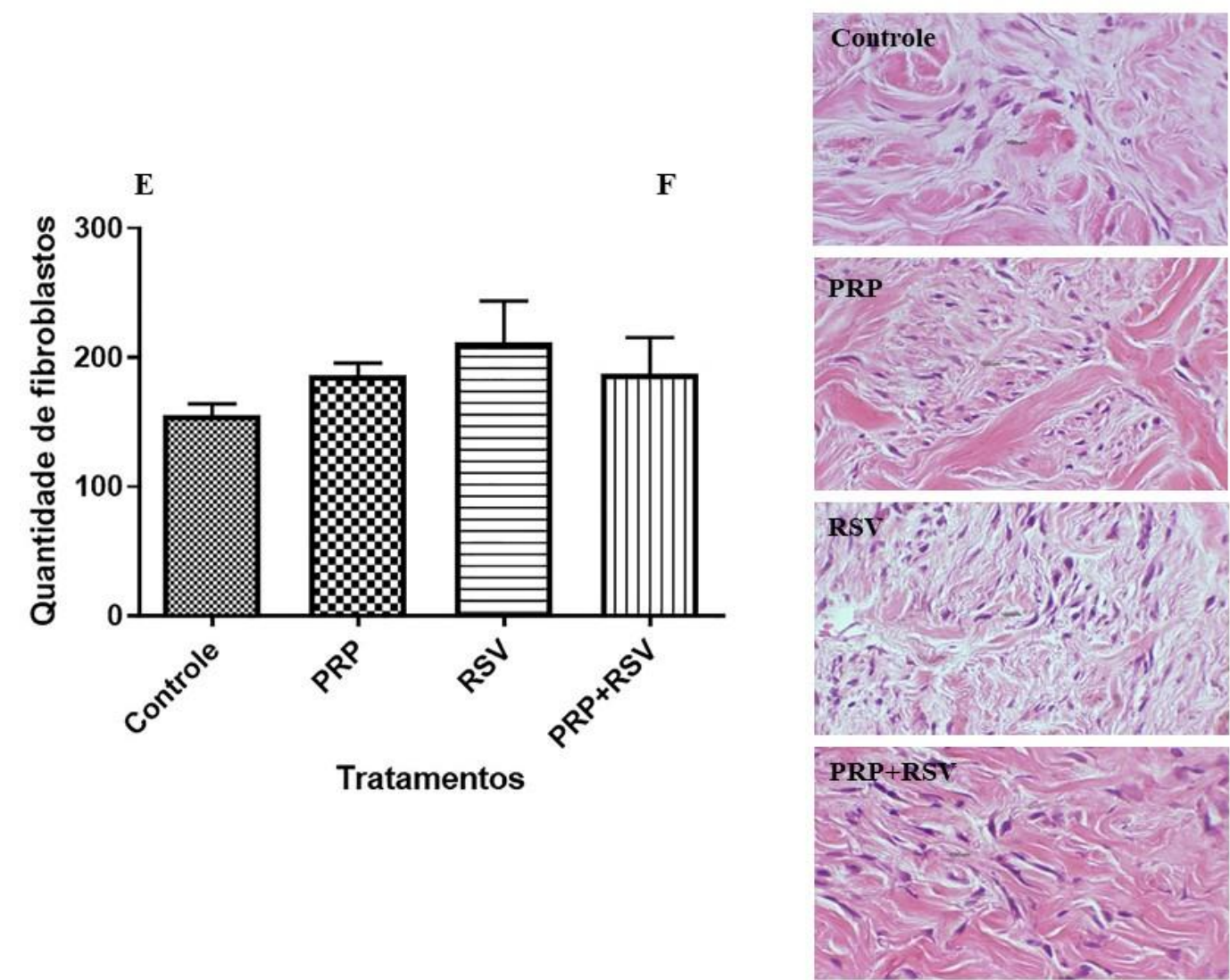

Figura 7. G:

Fonte: Autores. 
Figura 7. Média e desvio-padrão da quantidade de vasos de feridas de coelhos tratadas ou não com biomateriais e RSV. H: Fotomicroscopia mostrando a quantidade de vasos (Hematoxilina/Eosina, aumento de 100x). Controle, PRP: plasma rico em plaquetas, RSV: rosuvastatina, PRP+RSV: plasma rico em plaquetas e rosuvastatina.

4.

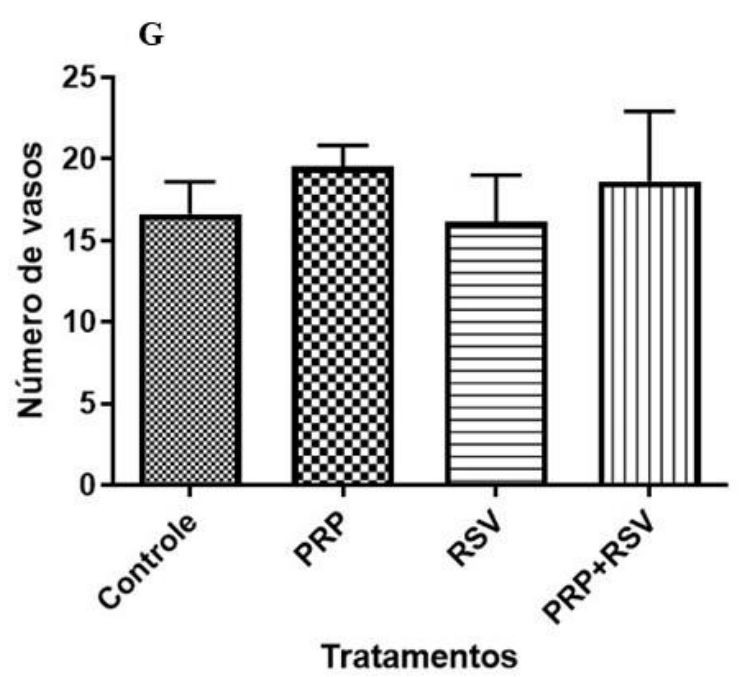

H
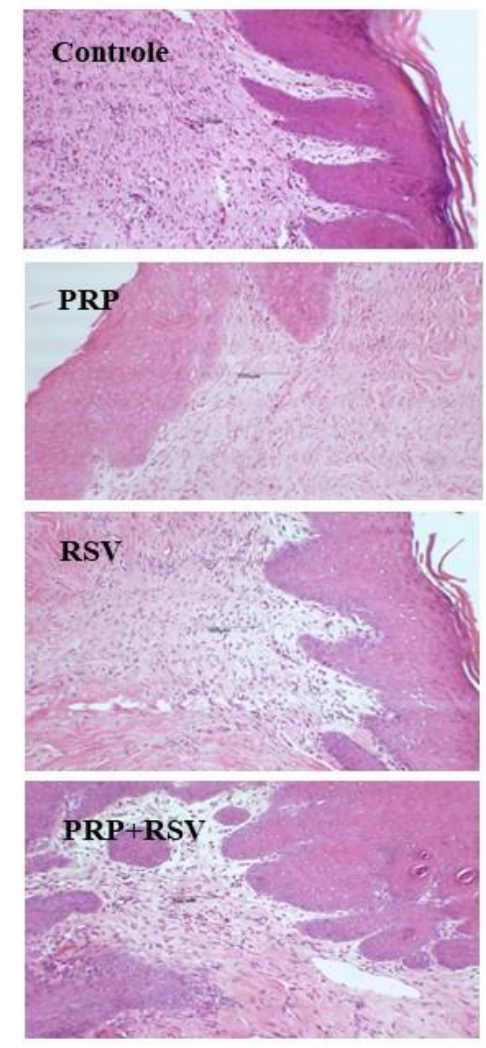

Fonte: Autores.

\section{Discussão}

Na quantificação dos fibroblastos, houve um aumento destas células nas feridas tratadas com RSV isolada. A associação da estatina com a FRP mostrou-se promissora. O fato de que a RSV, nos índices avaliados, melhorou os efeitos da FRP quando associada frente a seu uso isolado, denotando um efeito positivo e possivelmente sinérgico. Esta associação pode estar relacionada ao efeito de veicular substâncias que este biomaterial possui, como relatado por Miron e Zhang (2018), demonstrando essa característica por meio de estudos já publicados com a utilização da versão líquida da FRP associada a substâncias de baixo e alto peso molecular.

O mesmo efeito foi encontrado por Pradeep et al. (2016) em estudo clínico randomizado, utilizando associação de FRP e rosuvastatina a 1,2\% no tratamento de defeitos intraósseos na periodontite crônica, observando efeito sinérgico da rosuvastatina frente ao potencial regenerativo da FRP.

Os efeitos da FRP são diversos, sendo a ação cicatrizante o enfoque de muitos estudos. Roy et al. (2011) comprovaram a ação angiogênica da FRP em feridas isquêmicas, induzida por meio da proliferação de células endoteliais. Neste estudo o autor analisa a neovascularização por meio de anticorpos anti-fator de von Willebrand (vWF), mostrando aumento de células vasculares endoteliais. No nosso estudo a angiogênese foi avaliada por meio da quantificação de vasos sanguíneos observados, 
encontrando-se maiores quantidades, estatisticamente diferentes ( $\mathrm{p}<0,05)$, nos grupos tratados com a FRP. Dohle et al. (2018) por meio de culturas celulares in vitro demonstraram o efeito cicatrizante, em particular o efeito angiogênico da FRP, fato que corrobora nosso estudo.

Lee et al. (2014) ao confeccionar um stent utilizando RSV, comprovaram seu efeito angiogênico com a formação de células endoteliais vasculares. Neste estudo a quantidade de vasos sanguíneos neoformados nas feridas utilizando-se RSV isolada foram maiores que os do controle, entretanto, sem diferença estatística.

No presente estudo, utilizando 200G de força relativa de centrifugação observou-se maiores valores de vasos sanguíneos neoformados nas feridas com a utilização de FRP quando comparado às demais, corroborando Kubesch et al. (2019) que demonstraram que a força relativa de centrifugação interfere nas características físico-químicas da FRP sólida, de tal forma que a centrifugação com força média (222G) promoveu a confecção de uma trama de fibrina menos densa e mais porosa, refletindo em uma diferença significativa no índice de vascularização, quando comparada à força mais elevada.

Em concordância Ehrenfest et al. (2017) já demonstravam que as características da centrífuga como os protocolos de centrifugação impactaram significativamente nas células, fatores de crescimento e arquitetura da fibrina rica em plaquetas, demonstrando também que a quantidade de fatores de crescimento encontrados na FRP está relacionada à presença de leucócitos neste biomaterial.

Em uma revisão de trabalhos publicados com intuito de melhor elucidar a utilização de estatinas para o tratamento de úlceras do pé diabético Pietrovski et al. (2012) concluindo-se que a utilização dessas moléculas é promissora, mas com carência de estudos para este enfoque, dentre os estudos analisados. Chiaravalloti et al. (2017) relataram a utilização da FRP como tratamento de uma ferida cirúrgica crônica com resultados satisfatórios, com o fechamento completo da área da ferida de difícil cicatrização com seis semanas de tratamento, concluindo-se também que a utilização deste biomaterial é promissora, mas que ainda faltam estudos para melhor descrever sua ação e aplicabilidade.

Segundo Carmona et al. (2011), em seus estudos verificaram que a utilização de concentrados de plaquetas autólogas acelerou a cicatrização de ferida, reduzindo a inflamação, estimulando a capacidade de regeneração dos tecidos lesionados em cavalos com doenças degenerativas do sistema musculoesquelético, tais como osteoartrite e tendinopatia uma vez que essas plaquetas segregam fatores de crescimento, que induzem a quimiotaxia, diferenciação e proliferação celulares, neovascularização, e produção de matriz extracelular. Resultado similar foi encontrado por Pazzini (2014), em que avaliou o uso do PRP em cirurgia reconstrutiva em coelhos, quanto a avaliação da exequibilidade da técnica, achados macroscópicos e histopatológicos. Os resultados encontrados neste estudo foram significativos quando se avaliou a proliferação vascular no grupo com PRP, no qual esse composto promoveu uma angiogênese no local da aplicação da cirurgia reconstrutiva, mas quando se avaliou a quantidade dessa proliferação vascular no grupo tratado, os resultados foram semelhantes entre os grupos experimentais, não apresentando diferença significativas.

O estudo de Pazzini (2014) corrobora com os resultados achados neste presente estudo, em que embora não tenha ocorrido uma melhora entre as variáveis nas análises histopatológicas, foi possível visualizar no lado tratado com PRP autólogo gel uma discreta proliferação de fibroblastos e colagenização, promovendo o suprimento de oxigênio e nutrição da ferida, favorecendo o processo cicatricial. Podemos relacionar tal fato com os fatores de crescimento presentes nas plaquetas, por serem atuantes na fase inicial da cicatrização (Fernández-Sarmiento et al., 2013), responsáveis por estimular a angiogênese, mitogênese, permeabilidade capilar, induzindo crescimento do tecido epitelial.

Lee et al. (2014) demonstrou que a utilização da rosuvastatina reduziu os índices de fibrose miocárdica, através da diferenciação das fibras de colágeno por meio de imunofluorescência. Em nosso estudo obtivemos menores índices de fibrose acentuada nas feridas tratadas com rosuvastatina frente aos demais grupos, entretanto observaram-se maiores quantidades de 
fibroblastos nestes mesmos grupos, diferindo-se estatisticamente dos demais ( $<<0,05)$.

Neste estudo além de não qualificar e quantificar as fibras de colágeno por meio de técnicas mais específicas, não se realizou a diferenciação morfológica entre fibroblastos e miofibroblastos, de tal forma que, os maiores índices de fibroplastia aliada à contração das feridas mais precoce e expressivas no tratamento FRP+RSV, podem justificar a divergência entre os achados, devido ao fato de que os miofibroblastos estão relacionados à contração da ferida e não à produção de colágeno propriamente dita (Darby et al., 2014), entretanto segundo Bochaton-Piallat et al. (2016) essa relação ainda não está totalmente elucidada.

\section{Conclusão}

Concluiu-se que tanto a RSV quanto a FRP possuem bons efeitos cicatrizantes, de tal forma que a associação entre elas foi benéfica e demonstrou um possível efeito sinérgico, aumentando em $135 \%$ a angiogênese. No que se refere à produção de fibroblastos, o uso isolado da RSV mostrou ser mais eficiente, com aumento em 77\% na quantidade destas células. Assim podese observar que a utilização da rosuvastatina e da FRP mostraram resultados benéficos e promissores no tratamento de feridas experimentais e que a associação das substâncias promove uma melhor qualidade de cicatrização.

\section{Apoio Financeiro}

Fundação de Amparo à Pesquisa do Estado de São Paulo (FAPESP-processo número 2016/25938-0).

\section{Referências}

Abegão, K. G. B., Bracale, B. N., Delfim, I. G., Santos, E. S., Laposy, C. B., Nai, G. A., Giuffrida, R., \& Nogueira, R. M. B. (2015). Effects of heterologous platelet-rich plasma gel on standardized dermal wound healing in rabbits. Acta Cirúrgica Brasileira, 30(3), 209-215.

Azevedo, M. C. M. P. S. Aplicação do PRF em medicina dentária. 2014. 29 f. Dissertação (Mestrado integrado em Medicina Dentária) - Faculdade de Medicina Dentária, Universidade do Porto, Porto - Portugal.

Barrionuevo, D. V., Laposy, C. B., Abegão, K. G. B., Nogueira, R. M. B., Nai, G. A., Bracale, B. N., \& Delfim, I. G. (2015). Comparison of experimentallyinduced wounds in rabbits treated with different sources of platelet-rich plasma. Laboratory Animals, 49(3), $209-214$.

Bochaton-Piallat, M-L., Gabbiani, G., \& Hinz, B. (2016). The myofibroblast in wound healing and fibrosis: answered and unanswered questions. F1000Research, 5, F1000 Faculty Rev-752.

Carmona, J. U., Lopez, C., \& Giraldo, C. E. (2011). Uso do concentrado de plaquetas autólogo como terapia regenerativa de enfermidades crónicas del aparato músculo-esquelética equina. Archivos de Medicina Veterinária, 43(1), 1-10.

Chiaravalloti, A. J., Zubkov, B., \& Zubkov, A. (2018). Treatment of a Chronic Cutaneous Surgical Wound With Platelet-Rich Fibrin. Dermatologic Surgery, 44(3), 449-452.

Cieslik-Bielecka, A., Choukroun, J., Odin, G., \& Ehrenfest, D. M. D. (2012). L-PRP/L-PRF in esthetic plastic surgery, regenerative medicine of the skin and chronic wounds. Current Pharmaceutical Biotechnology,13(7), 1266-1277.

Darby, I. A., Laverdet, B., Bonté, F., \& Desmoulière, A. (2014). Fibroblasts and myofibroblasts in wound healing. Clinical Cosmetic and Investigational Dermatology, 7, 301-311.

Dohle, E., Bagdadi, K. E., \& Sader, R. (2018). Platelet-rich fibrin-based matrices to improve angiogenesis in an in vitro co-culture model for bone tissue engineering. Journal of Tissue Engineering and Regenerative Medicine, 12(3), 598-610.

Ehrenfest, D. M. D., Andia, I., Zumstein, M. A., Zhang, C-Q., Pinto, N. R., \& Bielecki, T. (2014). Classification of platelet concentrates (Platelet-Rich PlasmaPRP, Platelet-Rich Fibrin-PRF) for topical and infiltrative use in orthopedic and sports medicine: current consensus, clinical implications and perspectives. Muscles, Ligaments Tendons Journal, 4(1), 3-9.

Ehrenfest, D. M. D., Pinto, N. R., Pereda, A., Jiménez, P., Del Corso M., Kang, B-S., Nally, M., Lanata, N., Wang, H-L., \& Quirynen, M. (2017). The impact of the centrifuge characteristics and centrifugation protocols on the cells, growth factors, and fibrin architecture of a leukocyte- and platelet-rich fibrin (L-PRF) clot and membrane. Platelets, 29(2), 171-184. 
Research, Society and Development, v. 10, n. 1, e32510111327, 2021

(CC BY 4.0) | ISSN 2525-3409 | DOI: http://dx.doi.org/10.33448/rsd-v10i1.11327

Fernández-Sarmiento, A., Dominguez, J. M., Granados, M. M., Morgaz, J., Navarrete, R., Carrillo, J. M., Gómez-Villamantos, R. J., Muñoz-Rascón, P., Martin de Las Mulas, J., Millán, Y., García-Balletbó, M., \&Cugat, R. (2013). Histological study of the influence of plasma rich in growth factors (PRGF) on the healing of divided achilles tendons in sheep. Journal of Bone \& Joint Surgery, 95 (3), 246-255.

Grover, H. S., Kapoor, S., \&Singh, A. (2016). Effect of topical simvastatin (1,2 mg) on gingival crevicular fluid interleukin-6, interleukin-8 and interleukin-10 levels in chronic periodontitis- a clinic biochemical study. Journal of Oral and Biology Craniofacial Research., 6(2), 85-92.

Kubesch, A., Barbeck, M., Al-Maawi, S., Orlowska, A., Booms, P. F., Sader, R. A., Miron R. J., Kirkpatrick, C. J., Choukroun, J., \& Ghanaati, S. (2019). A low-speed centrifugation concept leads to cell accumulation and vascularization of solid platelet-rich fibrin: an experimental study in vivo. Platelets, 30(3),329340.

Lee, C. H., Chang, S. H., Lin, Y. H., Liu, S-J., Wang, C-J., Hsu, M-Y., Hung, K-C., Yeh, Y-H., Chen, W-J., Hsieh, I-C., \&Wen, M-S. (2014). Acceleration of re-endothelialization and inhibition of neointimal formation using hybrid biodegradable nanofibrous rosuvastatin-loaded stents. Biomaterials, 35 (15), 4417 4427

Lin, L.-L., Huang, C.-C., Chen, J.-S., Wu T.-C., Leu, H-B., Huang, P.-H., Chang,T.-T., Lin, S.-J., \&Chenet, J.-W. (2014). Effects of pitavastatin versus atorvastatin on the peripheral endothelial progenitor cells and vascular endothelial growth factor in high-risk patients : a pilot prospective, double-blind, randomized study. Cardiovascular. Diabetology, 13, 111.

Miron, R. J., \& Zhang, Y. (2018). Autologous Liquid Platelet Rich Fibrin: a novel drug delivery system. Acta Biomaterialia, 75, 35-51.

Moraes, L. A., Vaiyapuri, S., Sasikumar, P., Ali, M. S., Kriek, N., Sage, T., \& Gibbins J. M. (2013). Antithrombotic actions of statins involve PECAM-1 signaling. Blood, 122 (18), p.3188-3196.

Pazzini, J. M. (2014). Plasma rico em plaquetas empregado na cirurgia reconstrutiva em coelhos (Oryctolagus cuniculus): Avaliação da exequibilidade da técnica, achados macroscópicos e histopatológicos. Dissertação 88f. Universidade Estadual Paulista, Faculdade de Ciências Agrárias e Veterinárias, Jaboticabal.

Pietrovski, E. F., Mascarenhas, L., Scheeren, E., \& Neves, E. B. (2012). Úlceras do pé diabético podem ser tratadas com estatinas? Revista Brasileira de Farmácia, $93(3), 279-282$.

Pradeep, A. R., Karvekar, S., Nagpal, K., Patnaik, K., Guruprasad, C. N., \& Kumaraswamy, K. M. (2015). Efficacy of Locally Delivered $1.2 \%$ Rosuvastatin gel to non-surgical treatment of patients with chronic periodontitis: a randomized, placebo controlled clinical trial. Journal of Periodontology, 86 (6), $738-745$.

Pradeep, A. R., Karvekar, S., Nagpal, K., Patnaik, K., Raju, A., \&Singh, P. (2016). Rosuvastatin 1,2 mg in situ gel combined with 1:1 mixture of autologous platelet-rich fibrin and porous hydroxyapatite bone graft in surgical treatment of mandibular class II furcation defects: a randomized clinical control trial. Journal of Periodontology, 87(1), 5-13.

Raposio, E., Libondi, G., Bertozzi, N., Grignaffini, E., \& Grieco, M. (2015). Effects of topic simvastatin for the treatment of chronic vascular cutaneous ulcers: a pilot study. Journal of the American College of Clinical Wound Specialists, 7(1-3), 13-18.

Roy, S., Driggs, J., Elgharably, H., Biswas, S., Findley, M., Khanna, S., Gnyawali U., Bergdall, V. K., \&Sem, C. K. (2011).Platelet-rich fibrin matrix improves wound angiogenesis via inducing endothelial cell proliferation. Wound Repair Regeneration., 19(6), 753-766.

Santos, F. N., Watanabe, M., Ferreira Vasco, C., Dezoti da Fonseca, C., \& Fernandes Vattimo, M. F. (2014). Proteção antioxidante da estatina na lesão renal aguda induzida pela sepse. Revista da Escola de Enfermagem da USP, 48(5), 820-826.

Taniguchi, B. A. L., Breda, M. R. S., Nogueira, R. M. B., Nai, G. A., \& Laposy, C. B. (2018). Fractal features of rabbit dermal wounds treated with platelet-rich plasma and topical rosuvastatin. International Journal of Clínical and Experimental Pathology, 11(11), 5241-5248.

Vendramin, F. S., Franco, D., \& Franco, T. R. (2009). Método de obtenção do gel de plasma rico em plaquetas autólogo. Revista Brasileira de Cirugia Plástica, 24(2), 212-218.

Vendramin, F. S., Franco, D., \& Franco, T. R. (2010). Utilização do plasma rico em plaquetas (PRP) autólogo em enxertos cutâneos em coelhos. Revista Brasileira de Cirugia Plastica, 25(4), 4-10.

Zhang, S., Luo, L., Wang, Y., Rahman, M., Lepsenyi, M., Syk, I., Jeppsson, B., \& Thorlacius, H. (2012). Simvastatin Protects Against T Cell Immune Dysfunction in Abdominal Sepsis. Shock, 38 (5), 524-531. 